Ensaio

\title{
A Segurança Alimentar Via Sistemas Alimentares Circulares e as Controvérsias da Transição para os ODS
}

\author{
Food Security Via Circular Food Systems and the Transition \\ Controversies for the SDGs
}

Seguridad Alimentaria a Través de Sistemas Alimentarios Circulares y las Controversias de Transición para los ODS

La Sécurité Alimentaire Via les Systèmes Alimentaires Circulaires et les Controverses de Transition pour les ODD

Neli Apareciuda de Mello-Thèry ${ }^{1}$

\footnotetext{
${ }^{1}$ Geógrafa pela Universidade Federal de Goiás, Goiania, GO, Brasil; mestra em Arquitetura e Urbanismo pela Universidade de Brasília, Brasília, DF, Brasil, e em Géographie et Pratique du Développement pela Université de Paris Ouest-Nanterre-La Defense, Paris, França; doutora em Geographie pela Université de Paris Ouest-Nanterre-La Defense, Paris, França, e em Geografia Humana pela Universidade de São Paulo, São Paulo, Sp, Brasil e é Livre Docência em Gestão Ambiental pela Universidade de São Paulo São Paulo, SP, Brasil, e Livre Docente (Habilitation a diriger des recherches) pela Université de Rennes 2, Rennes, França. Atualmente é Professora Titular da Escola de Artes, Ciências e Humanidades, onde é docente no bacharelado de Gestão Ambiental, e dos Programas de Pós Graduação em Geografia Humana e Ciência Ambiental da Universidade de São Paulo, SP, Brasil.

E-mail: namello@usp.br
} 
Resumo

\section{Abstract}

Resumen
Considerando a segurança alimentar como um dos grandes desafios atuais, procura-se abordar como algumas controvérsias podem servir de impulso ou, ao contrário, criarem obstáculos para a adoção e implantação de metas vinculadas a Agenda 2030 das Nações Unidas. Procurando evidenciar a dimensão ambiental, esse ensaio estrutura-se em duas seções. A partir de uma introdução que aponta os vínculos entre padrões de alimentação e valores sociais, avança das teorias da transição ecológica para as controvérsias, conexões entre ecossistema, saúde humana e sistemas circulares e os atores envolvidos.

Palavras-Chave: Segurança Alimentar; Controvérsias; Objetivos do Desenvolvimento Sustentável; Sistemas Alimentares Circulares, Políticas Públicas.

Considering food security as one of the great current challenges, we seek to address how some controversies can serve as an impetus or, on the contrary, create obstacles to the adoption and implementation of goals linked to the United Nations Agenda 2030. Seeking to highlight the environmental dimension, this essay is structured in two sections. From an introduction that points out the links between food patterns and social values, it moves from theories of ecological transition to controversies, connections between ecosystem, human health and circular systems and the actors involved.

Keywords: Food Security, Controversies, Sustainable Development Goals; Circular Food Systems; Public Policies.

Considerando la seguridad alimentaria como uno de los grandes desafíos actuales, buscamos abordar cómo algunas controversias pueden servir de impulso o, por el contrario, crear obstáculos para la adopción e implementación de metas vinculadas a la Agenda 2030 de Naciones Unidas. Buscando resaltar la dimensión ambiental, este ensayo se estructura en dos secciones. A partir de una introducción que señala los vínculos entre los patrones alimentarios y los valores sociales, se pasa de las teorías de la transición ecológica a las controversias, las conexiones entre el ecosistema, la salud humana y los sistemas circulares y los actores involucrados.

Palabras Clave: Seguridad Alimentaria, Controversias, Objetivos de Desarrollo Sostenible; Sistemas Alimentares Circulares; Políticas Públicas. 
Resumé

Considérant la sécurité alimentaire comme l'un des grands défis actuels, nous cherchons à examiner comment certaines controverses peuvent servir d'impulsion ou, au contraire, créer des obstacles à l'adoption et à la mise en œuvre des objectifs liés à l'Agenda 2030 des Nations Unies. Pour mettre en évidence la dimension environnementale, cet essai est structuré en deux sections. D'une introduction qui souligne les liens entre les modes alimentaires et les valeurs sociales, il passe des théories de la transition écologique aux controverses, aux liens entre écosystème, santé humaine et systèmes circulaires et les acteurs impliqués.

Mots-clés: Sécurité Alimentaire, Controverses, Objectifs de Développement Durable; Politique Publique. 


\section{Indrodução ${ }^{1}$}

As tendências atuais das transições para os Objetivos do Desenvolvimento Sustentável abrangem a valorização da alimentação local e a inserção dos produtos da biodiversidade na dieta alimentar; a alteração de práticas agrícolas ultrapassadas e a redução das distancias na oferta de produtos alimentares.

Ainda que muitos destes produtos novos conquistem mercados e que a agricultura biológica, a agroecologia, a produção local com milhares de pequenas revoluções como Bénédicte Manier (2018) classificou, este tipo de abastecimento ainda é restrito a poucos que conseguem pagar por eles ou que se investem a produzir para seu próprio consumo. Comparado ao mercado mundial, não são ações e políticas centrais nem majoritárias. A produção em grande escala, a preços mais baixos, continua sendo a principal fonte de abastecimento mundial.

No entanto, os padrões de alimentação estão relacionados aos valores de cada sociedade, suas orientações, emoções, identidade individual e coletiva, tradição e cultura alimentar, a exemplo do Sistema Agrícola Tradicional do Rio Negro (BRAYNER, 2019). As taxas de comidas industrializadas são elevadas em países mais ricos e geram problemas de saúde e ambientais. Coloca-se, portanto, a problemática das escolhas: são elas individualizadas ou os governos devem dar recomendações de dietas? Fatos dessa ordem originam algumas das controvérsias identificadas neste processo.

Analisando a situação atual de produção de alimentos destinados ao consumo humano pode-se destacar o desperdício de 30\% a 50\% desses alimentos (HLPE, 2017). A perda de produtividade, de demanda de energia e recursos naturais impactam negativamente o ambiente, repercutindo na eutrofização, aumento de emissões de $\mathrm{CO}^{2}$ e outros gases de efeito estufa e na poluição atmosférica. Estas condições originaram teorias que impulsionam a transição para novos sistemas alimentares. Vamos nos ater à economia circular, que se caracteriza por três etapas: a) reduzir a quantidade de resíduos gerados no sistema alimentar, b) reutilizar alimentos, utilizar subprodutos e resíduos alimentares e c) reciclar nutrientes. São medidas que devem ser implementadas tanto pelo produtor quanto pelo consumidor, assim como na gestão do desperdício de alimentos e de excedentes alimentares.

Os hábitos alimentares baseados em dietas à base de carnes aumentaram a demanda por fosfato e geraram problemas de escassez do recurso e poluição da água. Este recurso está na lista das matérias-primas críticas da União Europeia. Neste contexto, a chave da segurança alimentar poderá ser o sistema circular com a recuperação e a reutilização do fosfato vindo de

\footnotetext{
1 Algumas das ideias colocadas neste ensaio puderam ser debatidas no decorrer do segundo semestre de 2018, no primeiro cohorte do MAK!T. O MAK'IT ((Montpellier Advanced Knowledge Institute on Transitions) foi criado no início de 2019 tendo entre seus objetivos testar a abordagem por controvérsias. Agradecemos as contribuições aos debates dos pesquisadores Dr. Habiba Bouhamed Chaabouni, Dr. Patrick Caron, Dr. Philippe Mayaud, Dr. John Porter, Dr. Martin Van Ittersum.
} 
múltiplas fontes (excrementos humanos e de animais, desperdício de alimentos e colheitas) e a melhora na eficiência de seu uso.

Na produção, os locais de pecuária bovina concentram excesso de P no solo. A exportação de carnes cria um comércio virtual de nutrientes-terra-água, usados na produção, mas não embutidos no preço do produto. Na geração de resíduos e excedentes, as perdas ocorrem em todas as fases do processo, da produção ao consumo. Em países de renda alta são de $40 \%$ no consumo; em países de baixa renda a perda se dá na produção em razão do nível tecnológico, da ineficiência nos transportes e logística ou nas condições de estocagem. 0 relatório do HLPE (2017) afirma que 30\% dos alimentos comestíveis produzidos para consumo humano são perdidos ou desperdiçados globalmente em toda a cadeia de fornecimento.

Em síntese, os argumentos para investir em uma agricultura baseada e otimizada no uso dos recursos produtivos estão contidos no sistema alimentar circular. A utilização integrada de recursos naturais regenerativos e uma biomassa associada deveria ser uma referência aos decisores políticos e suas agências de financiamento agrícola. Apesar de tantos argumentos positivos, há controvérsias que podem bloquear sua adoção.

\section{Da Transição Ecológica às Controvérsias Sobre as Conexões entre circularidade, Ecossistema e Saúde Humana}

Originadas no contexto das mudanças climáticas e da crise da biodiversidade, as teorias da transição ecológica fundamentam-se em duas abordagens: i) o uso responsável e sustentável dos recursos naturais que visa determinar as bases das políticas a serem configuradas, recorrendo à uma análise multicritérios dos setores energéticos e de exploração dos recursos e ii) governança da biodiversidade com usos de seus recursos, dos serviços ecossistêmicos, dos pagamentos pelos serviços ambientais ou de soluções sustentáveis inspiradas pela natureza. 0 conhecimento das composições específicas, das dinâmicas ecológicas, das condições meteorológicas e das evoluções com as mudanças climáticas é essencial.

Isto inclui a noção de resiliência dentro das transições, levando em conta as longas temporalidades portadoras de resiliência, assim como, o funcionamento bio-eco-físico dos territórios urbanos e áreas habitacionais, ligando às questões de justiça socioespacial. Demanda a apropriação das questões ambientais pelos participantes, implicando como as sociedades irão se posicionar para se antecipar às mudanças - as adaptações necessárias, as estratégias de atenuação e adaptação - considerando as dimensões ambientais, políticas, sociológicas, econômicas, psicológicas. Significa, portanto, transição para novos modelos. Mas, transições requerem inovações tanto sociais quanto tecnológicas.

As teorias de transição ecológica podem ser associadas às teorias das transições sociotécnicas multiníveis. Para Latour (2005) e Venturini (2015) as transições sociotécnicas são processos de transformação de longo prazo e fundamentais, através dos quais sistemas 
sociotécnicos estabelecidos mudam para modos de produção e consumo mais sustentáveis. Implicam, portanto, na necessidade de mudanças nas competências e práticas sociais, nas tecnologias e nas infraestruturas. As perspectivas multiníveis envolvem as experiências no micro-nível (local) e constituem as plataformas onde as novidades emergem. Estes nichos possuem configurações sociotécnicas instáveis em sua origem, com baixa performance. Estas experiências são desenvolvidas por pequenas redes de atores, as vezes externos. Cada experiência visa criar algo novo e concreto, restrito em termos de tempo, espaço, escopo e atores, mas que tem potencial relevância por meio de vários mecanismos de ampliação de escalas.

$\mathrm{Na}$ transição para a sustentabilidade, os experimentos de pequena escala oferecem oportunidades para o desenvolvimento de políticas locais e nacionais, olhando para o que foi negociado internacionalmente. Os desafios são conectados. 0 desenho e quadro conceitual das políticas deve ser elaborado com base nas barreiras e oportunidades identificadas e as estratégias para a transição devem ser simultaneamente bottom up e top down.

Baseio-me nas duas linhas de abordagem da transição ecológica, pois ambas impulsionam ao planejamento ambiental, ao planejamento dos diferentes ecossistemas naturais e humanos. Este tipo de planejamento visa criar caminhos para a modificação dos fluxos advindos a) da mudança de uso do solo em razão do avanço das fronteiras agrícolas (estas frentes provocam aumento de áreas utilizadas pela agricultura e pecuária, a utilização de pesticidas e da água para irrigação, a "expulsão" dos pequenos produtores para cidades, a perda da biodiversidade) e suas consequências sobre os ecossistemas naturais; b) alterações causadas nos diferentes ecossistemas naturais pelos modos de vida das sociedades, pelas atitudes coletivas que podem obrigar estas mesmas sociedades a perceber a importância dos mesmos e promoverem maneiras para se adaptarem. Tais fenômenos, analisados pelas lentes da transição ecológica, enfatizam sua relação com a água, a biodiversidade, a geração de resíduos e a dinâmica populacional (dos fluxos de migrações climáticas, por ex.).

Uma abordagem pelas transições visa considerar as controvérsias por elas originadas. Identificamos as mesmas como um mecanismo de ação, projeto de política e transições para o desenvolvimento sustentável. Do ponto de vista teórico, tem que levar em conta se tais elementos podem ser identificados nos debates públicos, societais ou científicos e, metodológicos. Alguns atores entrevistados no decorrer do segundo semestre de 2018 (primeiro cohorte do MAK!T) propõem que as mesmas sejam identificadas em sites, jornais e outros meios usados pela sociedade e somente depois basear-se nos papers científicos. Após esta identificação é recomendado que todas as opiniões sejam consideradas antes de elaborar uma análise do sistema de atores. As controvérsias têm que ser descritas de maneira precisa, identificando, pelo menos, 4 pontos para cada uma delas (os prós e os contras), apontando palavras-chaves.

Uma controvérsia sobre determinado tema pressupõe promover debates, dentre os quais pode se identificar conflitos, incertezas científicas e riscos tecnológicos, identificar conjunturas onde possam ocorrer multiplicidade de cenários e atores e que exigem a identificação de um conjunto de soluções e das reações que estas podem originar. Consequentemente, pode ser considerada uma situação de conflito na qual vários atores se opõem a vários assuntos relacionados a vários temas.

Estes fatores são muito importantes para a controvérsia "como pode ser conectado circularidade, ecossistemas e a saúde humana"? Estas três variáveis são interconectadas e destaco as conexões com os ecossistemas humanos que podem ser percebidas pelas 
1. possibilidade de recuperar áreas degradadas ou ainda a necessidade de mais superfície;

2. criação de novas bases para o desenvolvimento territorial usando os recursos da biodiversidade na alimentação;

3. políticas atuais que incentivam a circulação curta de alimentos (ou incentivam a manutenção dos sistemas convencionais?) e promove a redução de resíduos;

Dentre elas destaco algumas subcontrovérsias ambientais e possíveis caminhos:

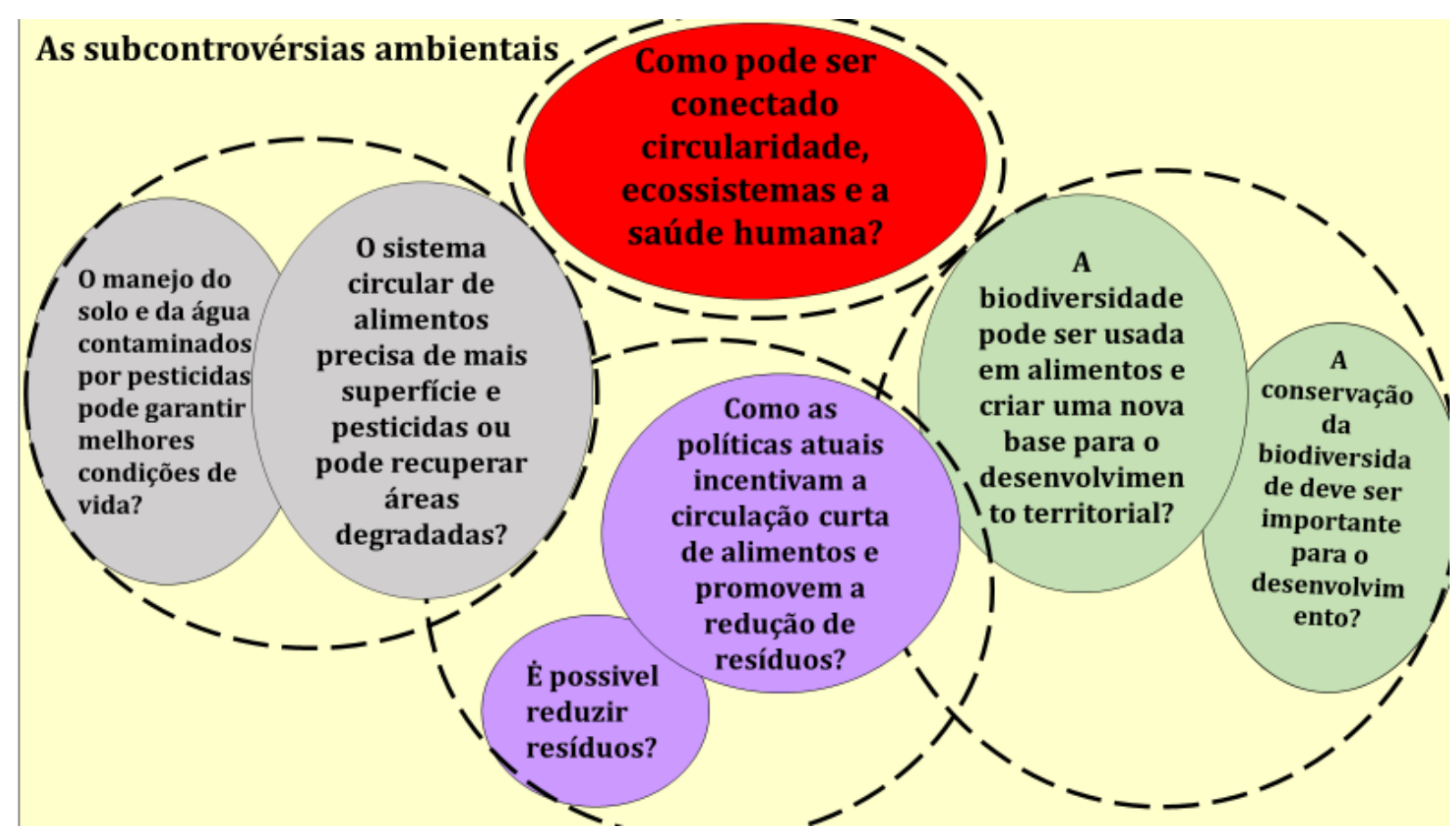

Fonte: Autoria própria.

1) 0 sistema circular precisa de mais superfície ou pode recuperar áreas degradadas?

a. recuperar solos degradados permite reduzir a conversão de áreas naturais em áreas de produção agrícola, porém o custo de recuperação é maior do que o da conversão;

b. pequenas cadeias de abastecimento/suprimento local reduzem armazenamentos, transportes e resíduos porém o preço dos produtos pode 
ser mais elevado decorrentes da escala de produção e não ser competitivo com as grandes redes de supermercados;

c. novos hábitos de consumidores valorizam estes aspectos e impacta positivamente porém, como sendo minoritários, não conseguem absorver toda a produção_(não criam demanda), dificultando a inserção destes produtores;

2) Pode a biodiversidade ser usada na alimentação e criar novas bases para o desenvolvimento territorial?

a. é possivel identificar produtos da biodiversidade específicos de cada ecossistema natural ou enriquecido pela sociedade, para serem introduzidos no sistema circular de alimentação, porém as políticas de desenvolvimento local fortalecem produtos e circuitos habituais de comercialização de alimentos;

b. a combinação de elementos locais e sazonais permite criar sistemas com produtos regionais, porém as políticas locais que estimulam produtos regionais são ainda marginais em relação aos circuitos tradicionais;

c. o desenvolvimento territorial sob estas bases depende de recursos financeiros e humanos capazes de apontar os elementos biodiversos que serão aproveitados, mas grupos tradicionais de produtores convencionais dominam as políticas públicas constituindo obstáculos

3) Como as políticas atuais incentivam a circulação curta de alimentos e promove a redução de resíduos?

a. valorizando o conhecimento das sociedades locais, suas maneiras de encurtar os circuitos produção-circulação e o uso de materiais não descartáveis.

Dentre os atores envolvidos nas subcontrovérsias pode-se ressaltar:

1. Produtores agrícolas e associações/cooperativas, ambientalistas, indústrias produtoras de agrotóxicos e de fertilizantes químicos, produtores de fertilizantes orgânicos, setor público ambiental e agrícola, decisores governamentais e dos setores produtivos

2. Ambientalistas, pesquisadores, organizações não governamentais, planejadores, produtores agrícolas, novos setores produtivos, empresas 
farmacêuticas, novos mercados de alimentação e de consumidores, decisores políticos

3. 3. Setores governamentais, sistemas de planejamento/saneamento, gestores de estações de tratamento de águas residuais, assistentes sociais, produtores de energia, mercados locais, consumidores

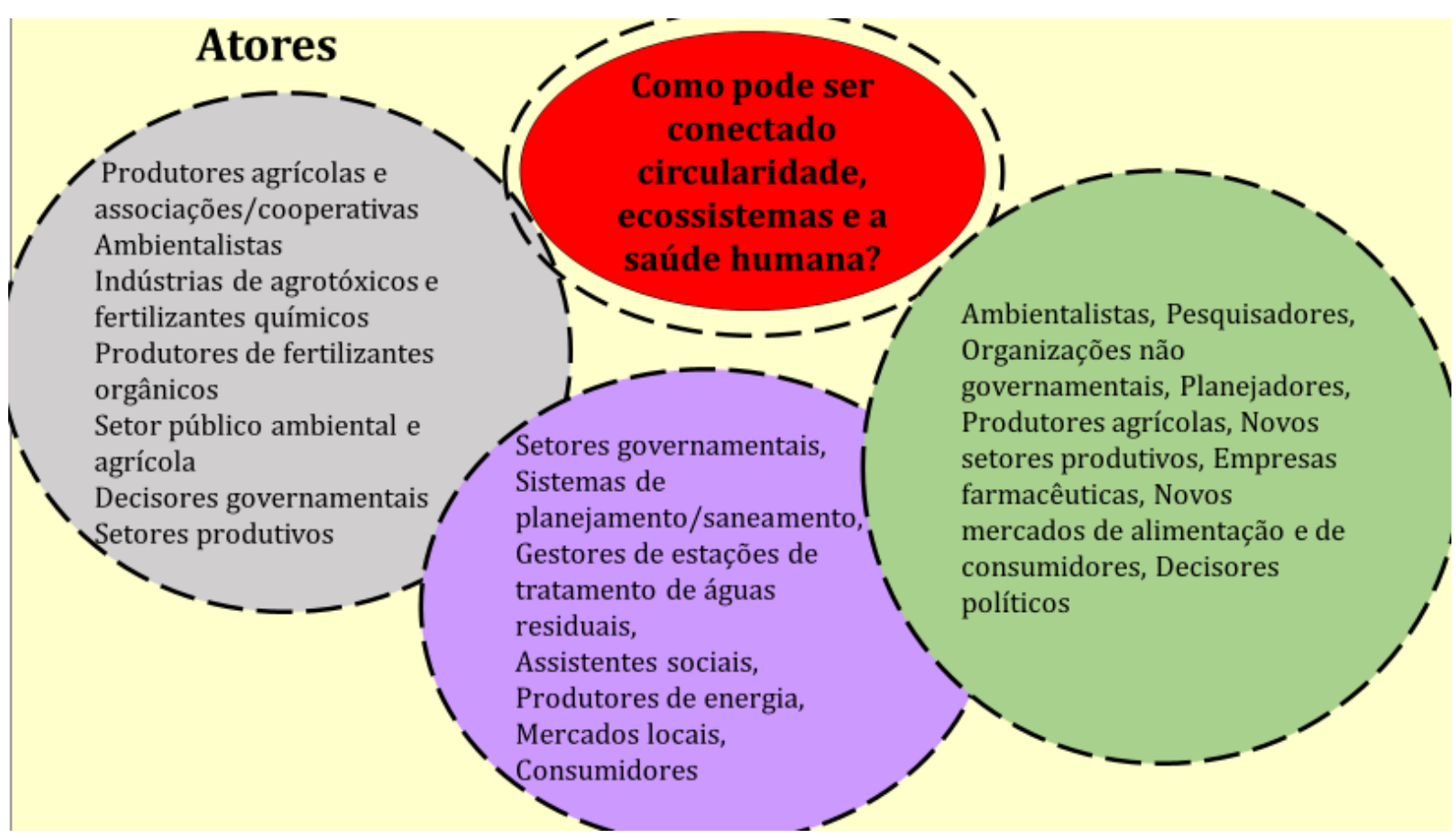

Fonte: Autoria própria.

Essas controvérsias estão estreitamente interligados à transição ambiental e aos Objetivos do desenvolvimento sustentável, destacando-se:

(2) = fome zero, apontando para uma agricultura sustentável;

(12) = consumo sustentável, especialmente voltado à falta de água potável e do desperdício de comida;

(13) = mudanças climáticas e

(17) = parcerias e meios de implementação. 
Apesar de que esses objetivos correspondem à luta constante contra a insegurança alimentar, atingindo populações mais vulneráveis nos diversos continentes, o processo de implementação não é facil e nem é consensual.

\section{Considerações Finais}

Ao vincular transições e controvérsias pode-se perceber o imenso desafio que as sociedades e os países têm pela frente. 0 que se esperava da Agenda XXI, no final do século XX, e se espera agora dos Objetivos do Desenvolvimento Sustentável é que o mundo perceba a necessidade de mudança e que se valorizem experiências sociais, científicas, políticas e empresariais diversificadas.

Sabemos que ocorrem muitas críticas a este processo e abordagem, assim como é um desafio modificar substancialmente o modelo existente mas, destacamos que é preciso pensar nas transições de todo o sistema em direção à sustentabilidade e na garantia de que todos os seres do planeta possam se alimentar de maneira saudável e sem causar maiores degradações ambientais, fazendo com que as milhares de pequenas revoluções se transformem em práticas centrais de políticas públicas. 


\section{Referências Bibliográficas}

Brayner, Natália Guerra. (2019). Da roça à mesa. Caminhos e sentidos da patrimonialização do Sistema Agrícola Tradicional do Rio Negro Em Eidt, Jane Simoni., \& Udry, Consolacion. (ed. tec.). Sistemas Agrícolas Tradicionais no Brasil. Brasília, DF : Embrapa, pp. 29-53.

HLPE. (2017). Nutrition and food systems. A report by the High Level Panel of Experts on Food Security and Nutrition of the Committee on World Food Security, Rome.

Latour, Bruno. (2005). Reassembling the Social: an introduction to Actor-Network-Theory. 1. ed. Hampshire: Oxford.

Manier, Bénédicte. (2018). Un million de révolution tranquilles. Paris : Editions J'ai Lu.

Venturini, Tommaso. (2015). Designing Controversies and their Publics. Design Issues, 29(4), 1730.

Recebido em 20/11/2018.

Aceito em 28/12/2018. 